\title{
НИЗКОТЕМПЕРАТУРНАЯ АТМОСФЕРНАЯ ПЛАЗМА В КОРРЕКЦИИ ВОЗРАСТНЫХ ИЗМЕНЕНИЙ КОЖИ ЛИЦА
}

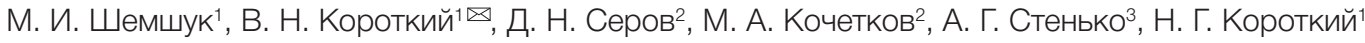

${ }^{1}$ Кафедра дерматовенерологии, Российский национальный исследовательский медицинский университет им. Н. И. Пирогова, Москва

2 Московский научно-практический центр дерматологии и косметологии, Москва

${ }^{3}$ Институт пластической хирургии и косметологии, Москва

\begin{abstract}
В антивозрастной терапии кожи лица стандартно используют ультрасиолетовое облучение, обработку поверхности кожи озоном и оксидом азота и воздействие электромагнитным полем. Низкотемпературная атмосферная плазма (НТП) способна оказать все эти воздействия. Целью работы было оценить эффективность НТП низкой интенсивности в качестве антивозрастной терапии кожи лица. Десяти пациенткам в возрасте 50-55 лет проводили исследование состояния кожи лица (Т-зону (центр лба), области «Гусиных лапок» справа и слева) на аппарате DUB SkinScaner до начала применения НТП и через сутки после 10 процедур. После очищения кожи ее обработали НТП низкой интенсивности, которую генерировали в среде гелия в виде плазменного факела на приборе «ГЕЛИОС» («НПЦ Плазма», Россия). Время экспозиции НТП составило 5 мин на каждую зону, процедуры проводили через день. До лечения состояние кожи лица всех участниц соответствовало третьему морфотипу инволюционных изменений. Ультразвуковое исследование (УЗИ) всех зон показало значительную десормацию микрорельефа, утолщение эпидермиса при сохранении четкой границы эпидермиса и дермы, некоторое снижение толщины дермы с однородной эхоструктурой, смазанное отграничение дермы от гиподермы. После завершения курса у всех пациенток отмечено уменьшение десормации микрорельефа, средней толщины эпидермиса и ультразвуковой плотности эпидермиса и дермы, тенденция к увеличению средней толщины дермы. Наибольшие изменения коснулись морщин: наблюдалось их сглаживание в области «гусиных лапок». Таким образом, использование НТП вызвало уменьшение толщины рогового слоя эпидермиса, улучшение микроциркуляции и улучшение качества гидролипидной мантии кожи, что сопровождалось сглаживанием морщин. Нежелательных явлений со стороны кожного покрова и придатков кожи не было отмечено.
\end{abstract}

Ключевые слова: возрастные изменения кожи, низкотемпературная атмосферная плазма, морщины

$\triangle$ Для корреспонденции: Владимир Николаевич Короткий

Ленинский пр-т, д. 117, корп. 6, г. Москва, 119571; vkbknk@gmail.com

Статья получена: 15.03.18 Статья принята к печати: 22.03.18

DOI: $10.24075 /$ vrgmu.2018.018

\section{NON-THERMAL ATMOSPHERIC-PRESSURE PLASMA IN THE ANTI-AGE THERAPY OF FACIAL SKIN}

\author{
Shemshuk $\mathrm{Ml}^{1}$, Korotky VN ${ }^{1 凶}$, Serov $\mathrm{DN}^{2}$, Kochetkov $\mathrm{MA}^{2}$, Stenko $\mathrm{AG}^{3}$, Korotky $\mathrm{NG}^{1}$ \\ ${ }^{1}$ Department of Dermatology and Venerology, Pirogov Russian National Research Medical University, Moscow \\ ${ }^{2}$ Moscow Research and Medical Center of Dermatology and Cosmetology, Moscow \\ ${ }^{3}$ Institute of Plastic Surgery and Cosmetology, Moscow
}

Traditionally, anti-age therapies employ ultraviolet radiation and exposure to ozone, nitric oxide and electromagnetic fields. Non-thermal atmospheric-pressure plasma (NTAPP) combines the effects of all those techniques. The aim of our study was to assess the feasibility of low-dose NTAPP application in anti-age facial skin therapy. Ten female patients aged 50 to 55 years were examined and three facial zones were chosen for the experiment: the T-zone (the central part of the forehead) and the "crow's feet" areas on the right and left sides of the face. Ultrasonography was performed on the DUB SkinScaner before the treatment course and 24 hours after the last treatment. Cleansed skin was exposed to a low-energy NTAPP helium jet generated by the HELIOS system (Plasma Research and Production, Russia). Exposure time was 5 min per zone. Each participant received 10 NTAPP procedures on alternate days. Before therapy, the skin condition in all participants fitted into morphotype 3. Ultrasonography of the studied zones revealed a considerable deformation of the skin surface, a thickening of the epidermis with a distinct border between the epidermis and the dermis, a slight thinning of the dermis, its relatively homogenous echogenicity, and a blurred border between the dermis and the hypodermis. After the course was completed, all patients demonstrated an evener skin surface, reduced epidermal thickness and reduced acoustic density of the epidermis and the dermis; the dermis tended to have above average thickness. The most significant changes were observed for the wrinkles: they became less pronounced in the "crow's feet" area. Exposure to NTAPP caused the epidermal corneum to diminish in thickness; it also stimulated microcirculation and improved the condition of the hydrolipidic film, all of which ultimately led to the effacement of wrinkles. Treatment produced no adverse effects on the skin or its appendages.

Keywords: skin aging, non-thermal atmospheric-pressure plasma, wrinkles

Correspondence should be addressed: Vladimir Korotky

Leninsky 117, bl. 6, Moscow, 119571; vkbknk@gmail.com

Received: 15.03.18 Accepted: 22.03.18

DOI: 10.24075/brsmu.2018.018 
Старение кожи - это первый видимый признак возрастных изменений, происходящихв организме. Различают два типа старения: хронологическое (внутреннее) и фотостарение (внешнее) [1]. Для хронологического старения характерно уменьшение общей толщины эпидермиса на 10-50\%, атрофия шиповатого слоя, уменьшение в размерах и уплощение клеток базального слоя, снижение митотической активности базальных кератиноцитов, снижение скорости процессов обновления липидов, уплощение дермоэпидермального соединения, снижение количества и гетерогенности меланоцитов, снижение количества клеток Лангерганса. В дерме при этом типе старения снижается количество фибробластов, происходит атросия межклеточного матрикса, дезинтеграция коллагеновых и эластических волокон и их уменьшение, откладывается амилоид. Все эти инволюционные изменения приводят $\mathrm{K}$ активации деформационных процессов и образованию морщин. Фотостарение это неизбежное изменение кожи от воздействия агрессивной внешней среды, ее увядание. Симптомы увядания кожи появляются задолго до появления первых морщин. Морфофункциональные признаки фотостарения кожи принято разделять на изменения, происходящие в эпидермисе и дерме. Визуально фотостарение характеризуется возникновением сосудистых звездочек, пигментных пятен (лентиго).

Главными отличиями фотостаренияотхронологического (истинного) старения являются утолщение эпидермиса за счет рогового слоя и изменение межклеточного вещества в дерме - накопление аморфного атипичного материала, состоящего из эластина. Стоит отметить, что способность дермы синтезировать коллаген и другие компоненты межклеточного вещества сохраняется, поэтому многие признаки фотостарения обратимы.

Внешне признаки старения имеют разные проявления, поэтому сейчас выделяют пять морфотипов старения [2]:

- 1 морфотип - «усталое лицо»: пастозность лица, опущение уголков рта;

- 2 морфотип - «морщинистое лицо»: выраженность морщин в уголках глаз (гусиные лапки), морщины верхнего и нижнего века, кисетные морщины в области верхней губы;

- 3 морфотип - старческая деформация лица и шеи: визуализируется избыток кожи в области верхнего и нижнего века, появление обвисших щек и двойного подбородка;

- 4 морфотип — комбинированный: к вышеперечисленным проявлениям присоединяются пониженная упругость, морщинистость и деформация;

- 5 морфотип - мускулистый: внешне отмечается складчатость верхнего и нижнего века, выраженность носогубной складки, сглаженность линии овала; чаще встречается у жителей Азии и Японии, у которых значительно развиты мышцы лица и незначительно выражена подкожно-жировая клетчатка.

С возрастом кожа истончается, становится бледной, ее эластичность и упругость снижаются, изменяется рельеф. Возрастные структурные перестройки затрагивают все зоны кожи: эпидермис, дерму и подкожно-жировую клетчатку. В коже молодых людей четко визуализируются структурные зоны, эпидермис имеет сосочковый рисунок, дерма плотная, подкожно-жировая клетчатка образует хорошо заметный слой [2]. Кожа пожилых истончается и утрачивает четкость структурной организации [2]. Сосочковый рисунок эпидермиса сглаживается, за счет чего площадь контакта эпидермиса и дермы уменьшается [2]. Волокнистый каркас дермы рыхлый, наблюдаются признаки отека [2]. Визуализируются морщины, подкожножировая клетчатка склерозирована и в этой связи не имеет четких границ с дермой.

Возрастные изменения кожи лица и возможность коррекции инволюционных изменений интересуют не только пациентов, но и врачей-косметологов. В настоящее время для борьбы с возрастными изменениями кожи лица используют многочисленные терапевтические воздействия, в том числе специальные косметологические средства, химический пилинг, различные физиотерапевические методы как в виде монотерапии, так и комбинированными [3-5]. Все они направлены на восстановление воднолипидной мантии кожи, водного баланса эпидермиса и дермы, а также на повышение микроциркуляции во всех слоях кожи, что сопровождается улучшением синтеза коллагеновых волокон [3]. Однако перечисленные меры имеют немало неприятных, порой грозных нежелательных явлений. При косметологическом уходе за стареющей кожей лица, шеи и области декольте нередко развиваются различные аллергические реакции [5], при химическом пилинге - покраснение, шелушение, отек и/или пигментация обработанной кожи [5], при физиотерапевтическом воздействии на кожу 一 появление демаркационной линии, нарушение пигментации кожи (гипер- или гипопигментация), рубцовые изменения, термические ожоги, болевые ощущения, атония кожи, электротравма [6]. В связи с этим поиск эфффективных и безопасных методов воздействия на инволюционные изменения продолжается и по настоящее время. Так, в ряде экспериментов была показана способность «холодной» (низкотемпературной) атмосферной плазмы (НТП) при малой интенсивности воздействия улучшать трофику тканей, повысить способность структур кожи к регенерации [7-10].

Новым неинвазивным методом, объединяющим в себе одновременно и действие ультрафиолетового излучения (УФ), и обработку поверхности озоном и оксидом азота, и воздействие электромагнитным полем, является НТП [8-12]. Плазма в физическом смысле - это частично или полностью ионизированный газ, так называемое четвертое состояние материи. НТП генерируется путем воздействия электромагнитного поля на газ при атмосферном давлении. Когда поле достаточно сильное, газовые ионы генерируются путем выделения электронов из молекул газа. Свободные электроны ускоряются электромагнитным полем и направляются к аноду, могут сталкиваться с молекулами газа, генерируя больше ионов газа и свободных электронов (ударная ионизация), что, в свою очередь, способствует образованию дополнительных молекул газа и т. д., приводя к генерации газовой плазмы при атмосферном давлении. Помимо электрического магнитного поля, свойства такой плазмы зависят от давления газа, типа используемого газа и геометрии излучателя $[12,13]$. НТП лишена основного недостатка других методов лечебного воздействия - высоких концентраций токсических веществ.

Основные действующие компоненты НТП — электроны, ионы, свободные радикалы и свет [13]. Свободные радикалы особенно важны в индукции физиологических функций клеток и тканей. Образующиеся под действием НТП активные формы кислорода и азота играют очень важную роль как в физиологических, так и патологических процессах, происходящих в различных клетках организма 
[14-16]. В последнее десятилетие созданы различные приборы, генерирующие НТП [17, 18], изучены эффекты прямого ее действия на липиды, белки, нуклеиновые кислоты живых клеток и опосредованного действия на сигнальные клеточные пути [15, 19].

В последние годы НТП начала использоваться в регенеративной медицине. Низкоинтенсивное воздействие НТП усиливает рост и пролиферацию клеток, в то время как высокоинтенсивное воздействие может привести к апоптозу или некрозу клеток, что подтверждает дозозависимый эффект оксидативного стресса [13, 20, 22]. При изучении интенсивности НПТ (количества энергии, которую НТП передает биологическим тканям) и ее воздействия на клетки млекопитающих было показано, что обработка НТП низкой интенсивности (не более 0,2 Дж/см²) приводит к пролиферации клеток, НТП средней интенсивности (0,2-0,6 Дж/см²) не оказывает никакого воздействия на клетки млекопитающих, а НТП высокой интенсивности (более 0,6 Дж/см²) вызывает апоптотическую гибель клеток $[19,22]$. Опубликовань результаты многочисленных исследований как еx vivo, так $n$ in vivo демонстрирующих антисептическое [2228] и ранозаживляющее действие НТП [9, 10, 29, 30]. Использование НТП высокой интенсивности нашло свое место в онкологии [20, 31] и в эрадикации различных возбудителей [21-28], а низкой интенсивности - в регенеративной медицине $[9,10,20,29,30]$.

В настоящей работе мы исследовали возможность использования НТП низкой интенсивности для улучшения состояния кожи лица при ее инволюционных изменениях в качестве антивозрастной терапии.

\section{ПАЦИЕНТЫ И МЕТОДЫ}

В исследовании, проводимом в сентябре-ноябре 2017 г. на кафедре дерматовенерологии ФГБУ ВПО РНИМУ им. Н. И. Пирогова, приняли участие 10 здоровых женщиндобровольцев в возрасте 50-55 лет, подписавших добровольное информированное согласие. Исследование одобрено Независимым этическим комитетом (протокол №2 от 08.02.2017 г.) и Ученым советом ГБУЗ Московский научно-практический центр дерматологии и косметологии Департамента здравоохранения г. Москвы (протокол №3 от 02.03.2017 г.). Критерии включения: добровольное согласие участвовать в исследовании, возраст 50-55 лет, женский пол, отсутствие воспалительных и инфекционных поражений кожи лица, нормальное содержание сахара в крови. Критерии исключения: наличие воспалительных и/или инфекционных поражений кожи лица; проведение любого вида антивозрастной терапии менее чем за 3 месяца до включения в настоящее исследование; наличие сахарного диабета, хронического заболевания почек или печени, васкулита или заболевания сердечнососудистой системы в стадии декомпенсации.

Всем участницам обследовали кожу лица: 1 зону Т-зону (лоб, центр), 2 зону - область «гусиных лапок» справа, 3 зону - область «Гусиных лапок» слева - на аппарате DUB SkinScaner (Digital Ultraschall Bildisystem, Германия), оснащенного двумя датчиками с частотами 22 и 75 МГц и разрешением 72 и 21 мкм соответственно с использованием датчика с центральной частотой 75 МГц. Обследование проводили до начала применения НТП и через сутки после проведения последней процедуры. В качестве проводника применяли стандартный ультразвуковой гель. Интерпретацию и анализ полученных данных осуществляли на оригинальном программном обеспечении к сканеру DUB-SkinScaner в соответствии с инструкцией. Исследование проводили при комнатной температуре в положении лежа. Измеряли среднюю толщину эпидермиса, среднюю толщину дермы, ультразвуковую плотность эпидермиса, ультразвуковую плотность дермы, микрорельеф (длину по наружному контуру эпидермиса), рассчитывали показатель деформации эпидермиса и коэффициент распределения ультразвуковой плотности в дерме (РузПД), т. е. отношение ультразвуковой плотности нижних отделов к ультразвуковой плотности верхних отделов; нормальное значение должно составлять от 0,75 до 1,70 ед. [33, 34].

После процедуры очищения проводили обработку кожи лица низкотемпературной атмосферной плазмой, генерируемой отечественным прибором «ГЕЛИОС» («НПЦ Плазма», Россия) (рис. 1), в среде инертного газа гелия по типу плазменного факела, получаемого при выходе гелия из баллона со скоростью 1,5 л/мин по шкале ротаметра со средней интенсивностью струи. Время экспозиции НТП составило 10 мин на область «гусиных лапок» с каждой стороны и 5 мин на межбровную область (Т-зона, проекция мышцы «гордецов»). Всего каждая участница получила по 10 процедур, проводимых через день.

\section{РЕЗУЛЬТАТЫ ИССЛЕДОВАНИЯ}

Состояние кожи лица всех пациенток до эксперимента расценивали как 3-й морфотип инволюционных изменений (пастозность лица, опущение уголков рта, выраженность морщин в уголках глаз («Гусиные лапки»), морщины верхнего и нижнего века, кисетные морщины в области верхней губы; избыток кожи в области верхнего и нижнего века), у одной - глубокий залом в межбровной области. На рис. 2А и ЗА представлены фото участниц исследования с типичными инволюционными изменениями кожи лица.

По результатам УЗИ (табл. 1) во всех зонах были отмечены значительная деформация микрорельефа, утолщение эпидермиса при сохранении четкой границы эпидермиса и дермы, некоторое снижение толщины дермы, ее достаточно однородная эхоструктура,

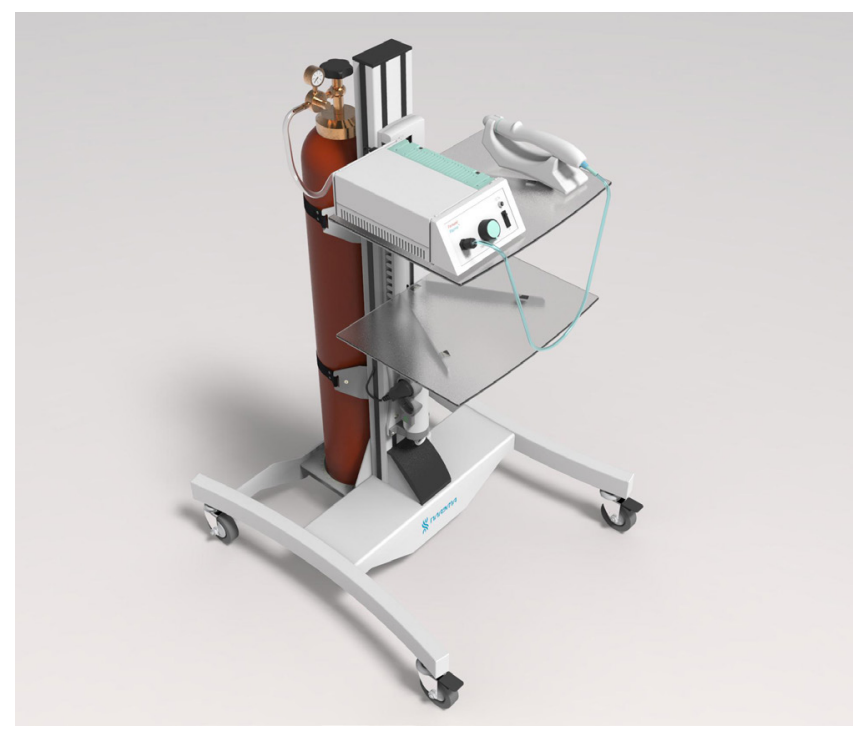

Рис. 1. Генератор низкотемпературной атмосферной плазмы «ГЕЛИОС», производства «НПЦ Плазма», Россия 
смазанное отграничение дермы от гиподермы. В одном случае (участница 50-ти лет) в Т-зоне визуализировался выраженный залом шириной 2867 мкм и глубиной 250 мкм (рис. 2A).

После завершения курса воздействия НТП на кожу лица у всех участниц исследования отмечена положительная динамика (табл. 1, рис. 2Б и ЗБ). Деформация эпидермиса уменьшилась в Т-зоне на 35\%, в области «Гусиных лапок» на 58\% и 30\%, справа и слева соответственно. При этом средняя толщина эпидермиса сократилась на 13,3\%, 5,0\% и 6,3\% соответственно. Снижение ультразвуковой плотности эпидермиса составило в Т-зоне 20\%, в области «гусиных лапок» справа 46,6\% и слева 35,6\%, что свидетельствует об улучшении трофики эпидермиса. Положительные изменения отмечены также в дерме. Средняя толщина дермы увеличилась в Т-зоне на 6\%, в области «Гусиных лапок» справа на 1,2\% и слева на 2,7\%. Ультразвуковая плотность дермы вместе с тем понизилась на 37,7\%, 20,6\% и 52,2\% соответственно. Отмеченные изменения тоже свидетельствуют о нормализации трофики дермы, гидратации ткани. В целом структура кожи в исследованных зонах существенно улучшилась, что подтверждается повышением значения РУзПД на 27,1\%, $11,9 \%$ и 30,3\% соответственно. Залом в межбровной области участницы 50-ти лет уменьшился в ширине, правда его глубина осталась прежней (рис. 2Б).

Наибольшие изменения отмечались со стороны микрорельефа в области «Гусиных лапок»: он стал более сглаженным, уменьшилась глубина морщин.

\section{ОБСУЖДЕНИЕ РЕЗУЛЬТАТОВ}

Известно, что при воздействии НТП происходит генерация большого количества активных форм кислорода и азота, УФ-протонов, электронов и различных ионов [32]. Экспериментально было показано увеличение микроциркуляции в коже под воздействием НТП низкой интенсивности, что сопровождается гидратацией и активизацией синтеза коллагена [33-35]. В коже здоровых добровольцев (мужчин и женщин старше 18 лет) под действием НТП улучшение микроциркуляции и снижение $\mathrm{pH}$ зависело от продолжительности воздействия [36]. Показано также, что под действием оксида азота, генерируемого НТП низкой интенсивности происходит активация $\beta$-катенина клетками эпидермиса, приводящая к регенерации клеток эпидермиса [37].

Для нормального функционирования эпидермиса необходим баланс между пролиферацией кератиноцитов и их апоптозом (естественной гибелью клеток), повторяющееся воздействие НТП на поврежденную кожу приводит к нормализации толщины эпидермиса и быстрой регенерации [37]. В настоящее время НТП используется для микробной деконтаминации и ускорения заживления ран и трофических язв, возможность применения НТП в регенеративной медицине тоже является предметом изучения. Наше исследование подтверждает безопасность применения НТП на коже пациентов. Мы показали, что после 10 процедур обработки кожи лица отмечается статистически значимое уменьшение ультразвуковой

Таблица 1. Результаты УЗИ кожи лица по зонам до и после курса воздействия $\mathrm{HTП}(\mathrm{M} \pm \sigma)$

\begin{tabular}{|c|c|c|c|c|c|c|}
\hline \multirow{2}{*}{ Показатель } & \multicolumn{3}{|c|}{ До обработки кожи НТП } & \multicolumn{3}{|c|}{ После обработки кожи НТП } \\
\hline & 1 зона & 2 зона & З зона & 1 зона & 2 зона & З зона \\
\hline Микрорельеф, мм & $13,2 \pm 0,1$ & $13,2 \pm 0,3$ & $13,1 \pm 0,2$ & $13,1 \pm 0,1$ & $12,9 \pm 0,08$ & $13,02 \pm 0,13$ \\
\hline Деформация эпидермиса, ед. & $0,416 \pm 0,07$ & $0,43 \pm 0,26$ & $0,33 \pm 0,18$ & $0,27 \pm 0,09^{*}$ & $0,18 \pm 0,08^{*}$ & $0,23 \pm 0,13^{*}$ \\
\hline Толщина эпидермиса, мкм & $72,9 \pm 12,3$ & $64,3 \pm 10,0$ & $65,1 \pm 7,8$ & $63,3 \pm 8,2^{*}$ & $61,1 \pm 8,7^{*}$ & $61,0 \pm 9,8^{\star}$ \\
\hline УЗ-плотность эпидермиса, ед. & $142,1 \pm 12,8$ & $106,6 \pm 7,2$ & $125,6 \pm 28,7$ & $113,7 \pm 24,0^{*}$ & $56,9 \pm 21,0^{*}$ & $82,1 \pm 33,7^{*}$ \\
\hline Толщина дермы, мкм & $1521,6 \pm 249,8$ & $1313,4 \pm 121,1$ & $1292,4 \pm 106,1$ & $1612,4 \pm 168,0^{*}$ & $1329,1 \pm 136,4^{*}$ & $1326,4 \pm 92,4^{*}$ \\
\hline УЗ-плотность дермы, ед. & $11,4 \pm 6,7$ & $19,9 \pm 14,6$ & $20,7 \pm 10,8$ & $7,1 \pm 4,7$ & $15,8 \pm 14,8$ & $9,9 \pm 5,1$ \\
\hline РУзПд & $0,70 \pm 0,11$ & $1,09 \pm 0,16$ & $0,944 \pm 0,191$ & $0,89 \pm 0,14^{*}$ & $1,22 \pm 0,18^{*}$ & $1,23 \pm 0,28^{*}$ \\
\hline
\end{tabular}

Примечание: РУзПД - распределение ультразвуковой плотности в дерме; * - статистически значимые различия между соответствующими показателями до и после воздействия НТП ( $p<0,05)$.
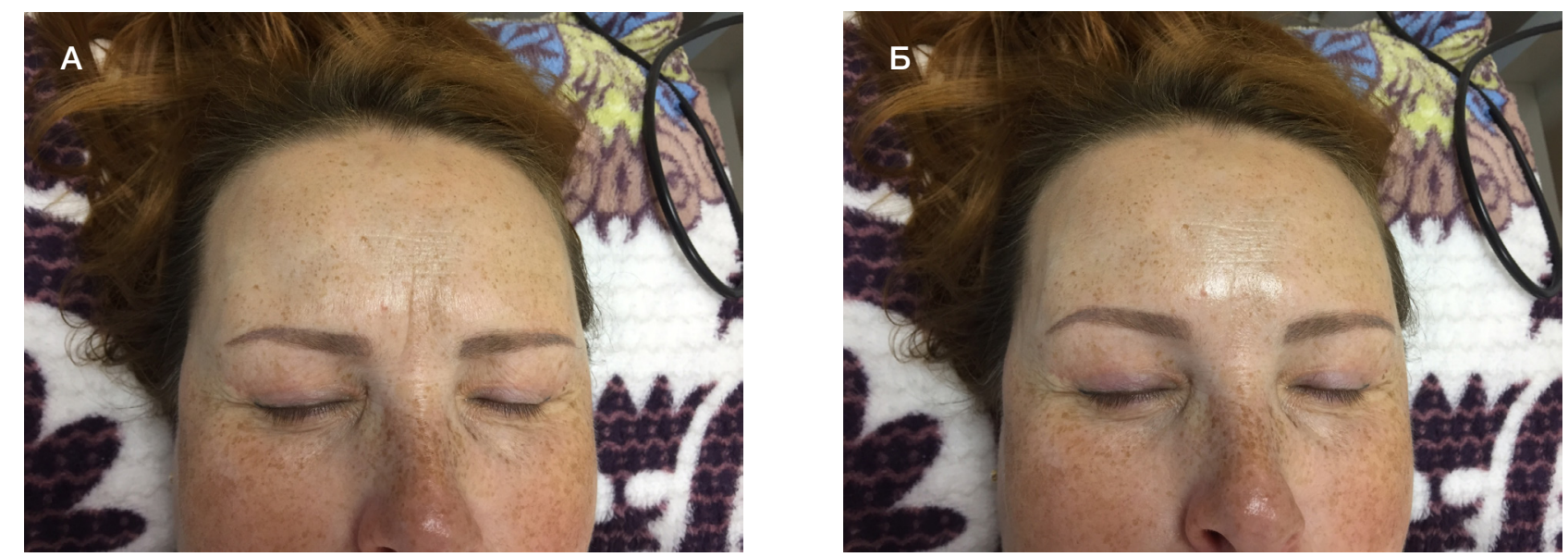

Рис. 2. Изменение межбровной области на фоне воздействия НТП. А. До воздействия. Б. После 10 процедур воздействия НТП 
A
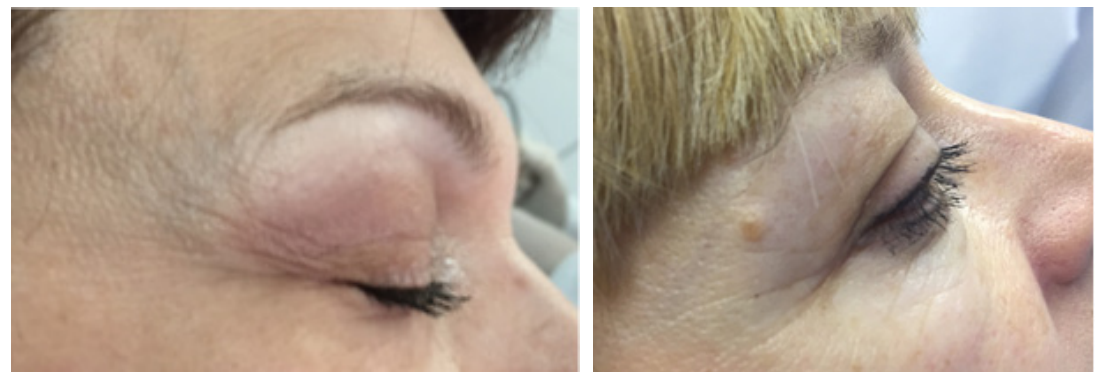

Б
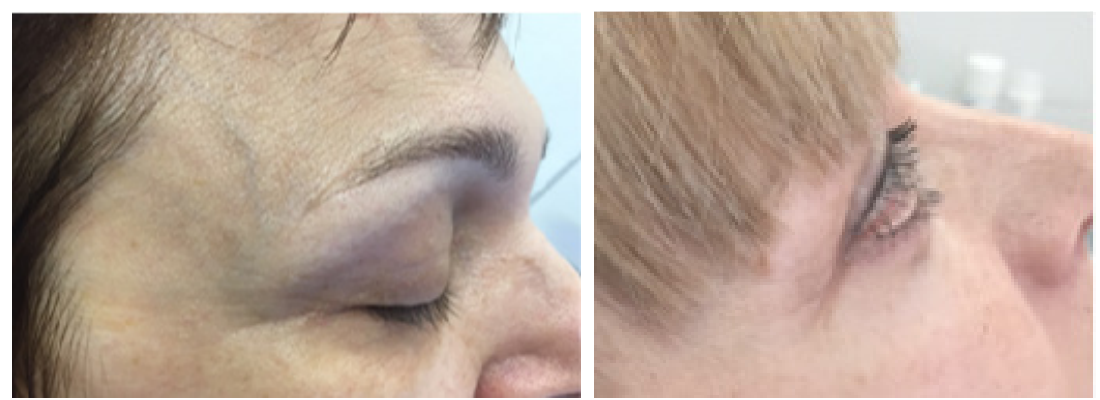

Рис. 3. Изменение кожи в области «гусиных лапок» лица справа. А. До воздействия. Б. После 10 процедур воздействия НТП

плотности эпидермиса, что свидетельствует об уменьшении избыточной толщины рогового слоя эпидермиса, улучшении микроциркуляции и улучшении качества гидролипидной мантии кожи, что согласуется с опубликованными экспериментальными данными [7, 12, 17, 33, 34]. Снижение ультразвуковой плотности дермы объясняется гидратацией глубоких структур кожи. Достигнутые изменения структуры кожи говорят об антивозрастном эффекте проводимых процедур. Все участницы исследования отметили визуальные улучшения кожи лица в виде уменьшения числа и глубины морщин в зонах исследования. До конца не ясным остается вопрос, какое количество процедур необходимо проводить и с какой кратностью для достижения максимального эффекта. Возможно, что выявленные нами положительные изменения структуры кожи лица оказались бы более значимыми при большем количестве процедур, что требует дальнейшего изучения.

\section{ВЫВОДЫ}

Физическое воздействие НТП малой интенсивности может существенно улучшить состояние эпидермального слоя кожи, сгладить морщины, появление которых ухудшает эмоциональное состояние женщин. Вместе с тем, какихлибо нежелательных явлений со стороны кожного покрова и придатков кожи в результате исследования мы не обнаружили. Необходимо продолжить клиническое исследование применения НТП в косметологии с целью отработки технологии проведения процедур и продолжительности курса для достижения максимального антивозрастного эффекта.

\section{Литература}

1. Zouboulis C, Makrantonaki E. Clinical aspect and molecular diagnostics of skin aging. Clinics in dermatology, 2011; 29: 3-14.

2. Борхунова Е. Н., Таганов А. В. Новая косметология. Микроскопические изменения кожи при старении. М.: ИД «Косметика и медицина», 2017. с. 74-102.

3. Ашер Б. Косметологические процедуры в области лица. Иньекционные методы в косметологии. М.: Изд. «МЕДпрессИнсорм», 2014; с. 179-215.

4. Труфанов В. Д., Коган Е. А., Юцковская Я. А., Файзулина Н. М., Иванов С. Ю. Радиоволны высокой частоты инновационный подход к коррекции возрастных изменений кожи; клиническое, иммуногистохимическое исследование. CTM. 2016; 8 (1): 106-16.

5. Марголина А., Эрнандес Е.. Новая косметология. М.: ИД «Косметика и медицина», 2015.

6. Саромыцкая А. Н.. Сочетанное применение фракционного фототермолиза и ботулинотерапии в коррекции гипертрофических и келоидных рубцовых десормаций кожи. М.: ИД «Косметика и медицина», 2016; с. 278-86.

7. Heinlin J, Morfill G, Landthaler M, Stolz W, Isbary G, Zimmermann J, Shimizu T, Karrer S. Plasma medicine: possible applications in dermatology. JDDG. 2010; 12: 968-76.

8. Okazaki $\mathrm{Y}$, Wang $\mathrm{Y}$, Tanaka $\mathrm{H}$, et al. Direct exposure of nonequilibrium atmospheric pressure plasma confers simultaneous

oxidative and ultraviolet modifications in biomolecules. J Clin Biochem Nutr. 2014; 55: 207-15.

9. Brehmer F, Haenssle HA, Daeschlein G, Ahmed R, Pfeiffer S, Gorlitz A, et al. Alleviation of chronic venous leg ulcers with a handheld dielectric barrier discharge plasma generator (PlasmaDerm( ${ }^{\circledR}$ ) VU-2010): results of monocentric, two-armed, open, prospective, randomized and controlled trial (NCTO1415622). J Eur Acad Dermatol Venereol. 2015; 29(1): 148-55.

10. Haertel B, von Woedtke Th, Weltmann K-D, Lindequist U. NonThermal Atmospheric-Pressure Plasma Possible Application in Wound Healing. Biol Therapeutics. 2014; 22: 477-90.

11. Akishev Y. Atmospheric pressure non-thermal plasma sterilization of microorganisms in liquids and on the surfaces. Pure and Applied Chemistry. 2008; 80 (9): 1953-69.

12. Laroussi M, Kong M, Morfill G, Stolz W (eds). Plasma medicine: application of low-temperature gas plasmas in medicine and biology. Cambridge University Press, 2012.

13. Короткий В. Н. Низкотемпературная атмоссерная плазма в дерматологии. Клиническая дерматология и венерология. 2017; 16 (5): 4-11.

14. Toyokuni S. The origin and future of oxidative stress pathology: from the recognition of carcinogenesis as an iron addiction with ferroptosis-resistance to non-thermal plasma therapy. Pathol Int. 2016; 66: 245-59. 
15. Hybertson BM, Gao B, Bose SK, McCord JM. Oxidative stress in health and disease: the therapeutic potential of Nrf2 activation. Mol Aspects Med 2011; 32: 234-46.

16. Uttara B, Singh AV, Zamboni P, Mahajan RT. Oxidative stress and neurodegenerative diseases: a review of upstream and downstream antioxidant therapeutic options. Curr Neuropharmacol. 2009; 7: 65-74.

17. Yousfi M, Merbahi N, Pathak A, Eichwald O. Low-temperature plasmas at atmospheric pressure: toward new pharmaceutical treatments in medicine. Fundamental \& Clinical Pharmacology. 2014; 28: 123-35.

18. Kalghatgi S, Friedman G, Fridman A, Clyne AM. Endothelial cell proliferation is enhanced by low dose non-thermal plasma through fibroblast growth factor-2 release. Ann Biomed Eng. 2010; 38: 748-57.

19. Kalghatgi S, Kelly CM, Cerchar E, Torabi B, Alekseev O, Fridman A, et al. Effects of non-thermal plasma on mammalian cells. PLoS ONE. 2011; 6: e16270.

20. Moureau M, Orange N, Feuilloley MGL. Non-thermal plasma technologies: new tools for bio-decontamination. Biotechnol Adv. 2008; 26: 610-17.

21. Shimizu T, Zimmermann JL, Morfill GE. The bactericidal effect of surface micro-discharge plasma under different ambient conditions. New Journal of Physics 2011; 13: 1-7.

22. Ermolaeva SA, Varfolomeev AF, Chernukha MY, Yurov DS Vasiliev MM, Kaminskaya AA, et al. Bactericidal effects of nonthermal argon plasma in vitro, in biofilms and in the animal mode of infected wounds. J Med Microbiol. 2011; 60: 75-83.

23. Ehlbeck J, Schnabel U, Polak M, Winter J, von Woedtke Th, Brandenburg R, et al. Low temperature atmospheric pressure plasma sources for microbial decontamination. J Phys D: Appl Phys. 2011; 44: 013002

24. Lademann O, Kramer A, Richter H, Patzelt A, Meinke MC, et al. Skin disinfection by plasma-tissue interaction: comparison of the effectivity of tissue-tolerable plasma and a standard antiseptic. Skin Pharmacol Physiol. 2011; 24: 284-88.

25. Maisch T, Shimizu T, Li Y-F, Heinlin J, Karrer S, Morfill G, et al Decolonisation of MRSA, S. aures and E. Coli by cold-atmospheric plasma using a porcine skin model in vitro. PLoS ONE. 2012; 7 : e34610.

26. Daeschlein G, Scholz S, Emmert S, von Podewils S, Haase H, von Woedtke Th. Plasma medicine in dermatology: basic antimicrobial efficacy testing as prerequisite to clinical plasma therapy. Plasma Med. 2012; 2 (1-3): 33-69.

\section{References}

1. Zouboulis C, Makrantonaki E. Clinical aspect and molecular diagnostics of skin aging. Clinics in dermatology, 2011; 29: 3-14.

2. Borhunova EN, Taganov FV. Novaya kosmetologia Mikroskopicheskoe izmenenie koghi pri starenii. M.: ID "Kosmetica i meditsina", 2017; s. 74-102.

3. Asher B. Kosmetologicheskie protseduri $\vee$ oblasti litsa In'ektsionnie metody v kosmetologii. Izd. "MEDpress-Inform», 2014; s. 179-215.

4. Trufanov VD, Kogan EA, Yutskovskaya JaA, Faizulina NM, Ivanov SYu. Radiovolni visokoy chastoti - innovatsionnil podhod k korrektsii vozrastnih izmenenii koghi; klinicheskoe, immunogistohimicheskoe issledovanie. STM. 2016; 8 (1); 10616.

5. Margolina A, Aernandes E. Novaya kosmetologiya. M.: ID "Kosmetika i meditsina», 2015.

6. Saromitskaya AN. Sochetannoe primenenie fraktsionirovannogo fototermoliza i botylinoterapii $\vee$ korrektsii gipertroficheskih i keloidnih rubtsovyh deformatsij koghi. M.: ID «Kosmetica i meditsina», 2016; s. 278-86.

7. Heinlin J, Morfill G, Landthaler M, Stolz W, Isbary G, Zimmermann J, Shimizu T, Karrer S. Plasma medicine: possible applications in dermatology. JDDG. 2010; 12: 968-976.

8. Okazaki $\mathrm{Y}$, Wang $\mathrm{Y}$, Tanaka $\mathrm{H}$, et al. Direct exposure of nonequilibrium atmospheric pressure plasma confers simultaneous
27. Daeschlein G, Napp M, von Podewils S, Lutze S, Emmert S., Lange $A$, et al. In vitro susceptibility of multidrug resistant skin and wound pathogens against low temperature atmospheric pressure plasma jet (APPJ) and dielectric barrier discharge plasma (DBD). Plasma Process Polymers. 2014; 11: 175-83.

28. Bekeschus S, Masur K, Kolata J, Wende K, Schmidt A Bundscherer $L$, et al. Human mononuclear cell survival and proliferation is modulated by cold atmospheric plasma jet. Plasma Process Polym. 2013; 10: 706-13.

29. Короткий В. Н. Возможности применения холодной атмосферной плазмы в онкологии (обзор литературы). Сибирский онкологический журнал. 2018; 17 (1): 72-81.

30. Безуглый А. П., Бикбулатова Н. Н., Шугинина Е. А., Белков П. А., Хабутдинова Н. Р. Ультразвуковое исследование кожи в практике врача-косметолога. Вестник Дерматологии Венерол. 2011; 3: 142-152.

31. Безуглый А. П., Потекаев Н. Н., Сапожникова Ю. А. Ультразвуковое сканирование высокого разрешения в дерматологии и медицинской косметологии. Экспериментальная и клиническая дерматокосметология. 2014; 2: 20-25.

32. Bibinov N, Knake N, Bahre H, Awakowicz P, von der Gathen VS. Spectroscopic characterization of an atmospheric pressure $\mu$-jet plasma source. J Phys D: Appl Phys. 2011; 44 (34): 345204.

33. Heuer K, Hoffmanns MA, Demir E, Baldus S, Volkmar CM, Röhle $\mathrm{M}$, et al. The topical use of non-thermal dielectric barrier discharge (DBD): nitric oxide related effects on human skin. Nitric Oxide. 2015; 44: 52-60.

34. Kisch T, Helmke A, Schleusser S, Song J, Liodaki E, Stang FH, Mailaender P, Kraemer R. Improvement of cutaneous microcirculation by cold atmospheric plasma (CAP): results of a controlled, prospective cohort study. Microvasc Res. 2016; 104: 55-62.

35. Kisch T, Schleusser S, Helmke A, Mauss KL, Wenzel ET, Hasemann B, et al. The repetitive use of non-thermal dielectric barrier discharge plasma boosts cutaneous micro- circulatory effects. Microvasc Res. 2016; 106: 8-13.

36. Borchardt T, Ernst J, Helmke A, Tanyeli M, Schilling AF, Felmerer $\mathrm{G}$, et al. Effect of direct cold atmospheric plasma (diCAP) on microcirculation of intact skin in a controlled mechanical environment. Microcirculation. 2017; 24: e12399.

37. Blanpain C, Fuchs E. Epidermal homeostasis: a balancing act of stem cells in the skin. Nat Rev Mol Cell Biol. 2009; 10: 207-17.

oxidative and ultraviolet modifications in biomolecules. J Clin Biochem Nutr. 2014; 55: 207-15.

9. Brehmer F, Haenssle HA, Daeschlein G, Ahmed R, Pfeiffer S, Gorlitz A, et al. Alleviation of chronic venous leg ulcers with a handheld dielectric barrier discharge plasma generator (PlasmaDerm $\left.{ }^{(}\right)$ VU-2010): results of monocentric, two-armed, open, prospective, randomized and controlled trial (NCTO1415622). J Eur Acad Dermatol Venereol. 2015; 29(1): 148-55.

10. Haertel B, von Woedtke Th, Weltmann K-D, Lindequist U. NonThermal Atmospheric-Pressure Plasma Possible Application in Wound Healing. Biol Therapeutics. 2014; 22: 477-90.

11. Akishev $Y$. Atmospheric pressure non-thermal plasma sterilization of microorganisms in liquids and on the surfaces. Pure and Applied Chemistry. 2008; 80 (9): 1953-69.

12. Laroussi M, Kong M, Morfill G, Stolz W (eds). Plasma medicine: application of low-temperature gas plasmas in medicine and biology. Cambridge University Press, 2012.

13. Korotky VN. Nizkotemperaturnaya atmosfernaya plasma v dermatologii. Klinicheskaya dermatologiya i venerologiya. 2017; 16 (5): 4-11.

14. Toyokuni S. The origin and future of oxidative stress pathology: from the recognition of carcinogenesis as an iron addiction with ferroptosis-resistance to non-thermal plasma therapy. Pathol Int. 2016; 66: 245-59. 
15. Hybertson BM, Gao B, Bose SK, McCord JM. Oxidative stress in health and disease: the therapeutic potential of Nrf2 activation. Mol Aspects Med 2011; 32: 234-46.

16. Uttara B, Singh AV, Zamboni P, Mahajan RT. Oxidative stress and neurodegenerative diseases: a review of upstream and downstream antioxidant therapeutic options. Curr Neuropharmacol. 2009; 7: 65-74.

17. Yousfi M, Merbahi N, Pathak A, Eichwald O. Low-temperature plasmas at atmospheric pressure: toward new pharmaceutical treatments in medicine. Fundamental \& Clinical Pharmacology. 2014; 28: 123-35.

18. Kalghatgi S, Friedman G, Fridman A, Clyne AM. Endothelial cell proliferation is enhanced by low dose non-thermal plasma through fibroblast growth factor-2 release. Ann Biomed Eng. 2010; 38: 748-57.

19. Kalghatgi S, Kelly CM, Cerchar E, Torabi B, Alekseev O, Fridman A, et al. Effects of non-thermal plasma on mammalian cells. PLoS ONE. 2011; 6: e16270.

20. Moureau M, Orange N, Feuilloley MGL. Non-thermal plasma technologies: new tools for bio-decontamination. Biotechnol Adv. 2008; 26: 610-17.

21. Shimizu T, Zimmermann JL, Morfill GE. The bactericidal effect of surface micro-discharge plasma under different ambient conditions. New Journal of Physics 2011; 13: 1-7.

22. Ermolaeva SA, Varfolomeev AF, Chernukha MY, Yurov DS, Vasiliev MM, Kaminskaya AA, et al. Bactericidal effects of nonthermal argon plasma in vitro, in biofilms and in the animal mode of infected wounds. J Med Microbiol. 2011; 60: 75-83.

23. Ehlbeck J, Schnabel U, Polak M, Winter J, von Woedtke Th, Brandenburg R, et al. Low temperature atmospheric pressure plasma sources for microbial decontamination. J Phys D: App Phys. 2011; 44: 013002

24. Lademann O, Kramer A, Richter H, Patzelt A, Meinke MC, et al. Skin disinfection by plasma-tissue interaction: comparison of the effectivity of tissue-tolerable plasma and a standard antiseptic. Skin Pharmacol Physiol. 2011; 24: 284-88.

25. Maisch T, Shimizu T, Li Y-F, Heinlin J, Karrer S, Morfill G, et al. Decolonisation of MRSA, S. aures and E. Coli by cold-atmospheric plasma using a porcine skin model in vitro. PLoS ONE. 2012; 7: e34610.

26. Daeschlein G, Scholz S, Emmert S, von Podewils S, Haase H, von Woedtke Th. Plasma medicine in dermatology: basic antimicrobial efficacy testing as prerequisite to clinical plasma therapy. Plasma Med. 2012; 2 (1-3): 33-69.
27. Daeschlein G, Napp M, von Podewils S, Lutze S, Emmert S., Lange $A$, et al. In vitro susceptibility of multidrug resistant skin and wound pathogens against low temperature atmospheric pressure plasma jet (APPJ) and dielectric barrier discharge plasma (DBD). Plasma Process Polymers. 2014; 11: 175-183.

28. Bekeschus S, Masur K, Kolata J, Wende K, Schmidt A, Bundscherer $L$, et al. Human mononuclear cell survival and proliferation is modulated by cold atmospheric plasma jet. Plasma Process Polym. 2013; 10: 706-13.

29. Korotky VN. Vozmoghnosti primenenija kholodnoy amosernoy plazmy $v$ onkologii (obzor literatury). Sibirskiy onkologicheskiy ghurnal. 2018; 17 (1): 72-81.

30. Bezuglii AP, Bikbulatova NN, Shuginina EA, Belkov PA, Habutdinova NR. Ul'trazvukovoe issledovanie koghi v praktike vracha-kosmetologa. Vestnik Dermatologii I venerologii. 2011; 3: 142-152.

31. Bezuglii AP, Potekaev NN, Sapoghnikova YuA. Ul'trazvukovoe skanirovanie visokogo razresheniya $v$ dermatologii i meditsinskoi kosmetologii. Eksperimental'naya i klinicheskaya dermatovenerologiya. 2014; 2: 20-25.

32. Bibinov N, Knake N, Bahre H, Awakowicz P, von der Gathen VS. Spectroscopic characterization of an atmospheric pressure $\mu$-jet plasma source. J Phys D: Appl Phys. 2011; 44 (34): 345204.

33. Heuer K, Hoffmanns MA, Demir E, Baldus S, Volkmar CM, Röhle $\mathrm{M}$, et al. The topical use of non-thermal dielectric barrier discharge (DBD): nitric oxide related effects on human skin. Nitric Oxide. 2015; 44: 52-60.

34. Kisch T, Helmke A, Schleusser S, Song J, Liodaki E, Stang FH, Mailaender $\mathrm{P}$, Kraemer R. Improvement of cutaneous microcirculation by cold atmospheric plasma (CAP): results of a controlled, prospective cohort study. Microvasc Res. 2016; 104: 55-62.

35. Kisch T, Schleusser S, Helmke A, Mauss KL, Wenzel ET, Hasemann B, et al. The repetitive use of non-thermal dielectric barrier discharge plasma boosts cutaneous micro- circulatory effects. Microvasc Res. 2016; 106: 8-13.

36. Borchardt $T$, Ernst $J$, Helmke $A$, Tanyeli $M$, Schilling AF, Felmerer $\mathrm{G}$, et al. Effect of direct cold atmospheric plasma (diCAP) on microcirculation of intact skin in a controlled mechanical environment. Microcirculation. 2017; 24: e12399.

37. Blanpain C, Fuchs E. Epidermal homeostasis: a balancing act of stem cells in the skin. Nat Rev Mol Cell Biol. 2009; 10: 207-17. 